УAK 321.01: [004:002]

ББК $66.02+73$

DOI 10.22394/1682-2358-2017-4-94-102

I.A. Bronnikov, Candidate of Sciences (Politics), Docent of the Russian Politics Department, Faculty of Political Science, Lomonosov Moscow State University

\section{CIVIL INTERNET \\ ACTIVISM: \\ TRENDS AND PROSPECTS}

The practice of civil Internet activism in the realities of the modern information society is considered. It is proved that in order to overcome the "communicative failure" between civil society and the state, it is necessary to integrate Internet activism into the political process. The main forms of civil Internet activism are highlighted. Particular attention is paid to the organization and conduct of electronic referenda.

Key words and word-combinations: civil society, civil Internet activism, electronic referenda, the Internet, information society.
И.А. Бронников, кандидат политических наук, доцент кафедри российской политики факультета политологии Московского государственного университета имени М.В. Аомоносова (email:ivbronn@gmail.com)

\section{ГРАЖААНСКИЙ ИНТЕРНЕТ-АКТИВИЗМ: ТЕНАЕНЦИИ И ПЕРСПЕКТИВЫ}

Аннотация. Рассматриваются практики гражданского интернет-активизма в реалиях современного информационного общества. Доказано, что для того чтобы преодолеть «коммуникативный провал» между гражданским обществом и государством, необходимо встраивание интернетактивизма в политический процесс. Изучаются основные формы гражданского интернет-активизма. Особое внимание уделено организации и проведению электронных референдумов.

Ключевые слова и словосочетания: гражданское общество, гражданский интернет-активизм, электронные референдумы, Интернет, информационное общество.

B последнее время многие государства мира столкнулись с проблемой недоверия к краеугольному камню демократических институтов - выборам, и, как следствие, глубокому кризису политического участия, связанному с общим абсентеизмом широких масс. С Аругой стороны, внедрение современных информационно-коммуникационных технологий (ИКТ) в политический процесс позвоцяет заинтересованным акторам многократно увекичить свое влияние на

94 Bulletin of the Volga Region Institute of Administration • 2017. Vol. 17. № 4 
политическую систему, а также артикулировать собственное мнение и вциять на формирование «повестки Аня». Россия не осталась в стороне от этого процесса.

Вхождение человечества в информационную стадию своего развития способствовало переосмыслению роли информаџии и знания. Начиная с 1960-х годов предиагалось множество теоретических моделей информационного общества, которые отражали суть происходящих быстроменяющихся событий. Несмотря на важные особенности, которые были выделены авторами конџепџий информационного общества, реалии XXI в. привели к тому, что сегодня они все чаще подвергаются обоснованной критике. Существующие концепции информационного общества бессильны с точки зрении операционализаџии темпоральной специфики современной соџиальной реальности. Критические замечания о возможности реализации информационного общества высказывали еще Ж. Бодрийяр (исчезновение информации), М. Кастельс (информациональный капитализм) и $\Lambda$. Аессиг (общество свободной культуры). Альтернативными соџиальными конџепџиями, преАложенными в последнее время, явцяются следующие:

1. Концепция «креативного общества». Особая роль в развитии реального сектора экономики отдается креативной индустрии и человеческому потенциалу.

2. Концепция «постинформационного общества». КАючевыми технологическими платформами явцяются: искусственный интемлект и интернет вещей, а постоянное искажение транслируемых сведений и информации свидетельствует о формировании новой соџиальной реальности общества постинформации со свойственным ему скептическим отношением к провозглашаемым истинам.

Среди отечественных авторов, высказывающих критические соображения относитеиьно концепции информационного общества, можно выдемить В.А. Иноземцева, В.Г. Горохова, А.И. Ракитова, С.В. Володенкова. По мнению В.А. Иноземцева, информационное общество - это понятие-абстракция, которое ничего не проясняет и не предполагает концептуализации. В.Г. Горохов предлагает называть современное общество «обществом не-знания», что связано с избытком информации низкого содержания, циркулирующей в социальном пространстве, а также с трансформацией науки под воздействием рыночных механизмов. А.И. Ракитов считает, что создание систем искусственного интемлекта (ИИ), искусственного суперинтелмекта (ИСИ), суперинтемлектуацьного человекоподобного интемлекта (УЧИ) будет означать переход от информационного общества к постинформационному.

Как показала практика, одной из проблем, вытекающей из реальности формирования постинформационного общества, стало то, что государство относится преимущественно технологически к политическим инновациям последних мет. Постоянное же искажение транслируемых сведений и информации приводит к Аисбалансу современных политических коммуникаций. Современный неиерархический мир пережкивает повсеместное политическое 
пробужждение - миммионы мюдей находятся в поиске своей идентичности. Пересматриваются исторические события, адаптируются политические решения, модифиџируются управленческие проџессы - мир политики ХХІ в. многолик. Ааже традиџионные понятия получают новое звучание. К примеру, недавно Оксфордский словарь пополнился словами, которые получили новый смысл. Так, слово «проснувшийся» (waken) теперь чаще используется в значении «осознанный» или «хорошо информированный», причем в политическом или культурном контексте.

Не в последнюю очередь этому способствовало развитие интернет-техномогий, которые открывают новые формы и методы взаимодействия власти и гражданского общества. Как известно, еще Ф. Шмиттер показал, что одна из кАючевых особенностей гражданского общества - это действия самоорганизованных посреднических групп, которые способны осмыслять и совершать комективные Аействия в защиту ими ради продвижения своих интересов и чувств [1, р. 240]. Аморфность гражданского общества проявцяется в слабоструктурированных и несформированных механизмах взаимодействия государства и общества. Внедрение интернет-коммуникаций в политический процесс активизировали гражданскую активность, которая обусловливает демократический процесс. В свое время $\Lambda$. Аессиг указывац, что противостоять наступмению информационных монополий может только гражданское общество с сильным гражданским самосознанием.

Выделяют четыре формы гражданского участия как адаптивной публичной активности, связанной с реализаџией универсальных прав и свобод:

- индивидуальное участие - деятельность отдельных граждан, использующих универсальные права и свободы для решения собственных или семейных проблем;

- комлективное участие - деятельность граждан или их ассоџиаџий, использующих универсальные права и свободы для решения проблем отдельных групп гражАан;

- общественное участие - деятельность отдельных индивидов или объединений граждан, использующих универсальные права и свободы Аля решения проблем, значимых дия большинства или всех граждан;

- глобальное участие - деятельность граждан или их ассоџиаций, ориентированная на международный режим прав человека, глобальные нормы [2, с. 25-26] .

Новых подходов Аискуссии добавило использование интернет-технологий Амя выражения всех обозначенных форм гражданского участия. Особенно ярко это проявилось после внедрения Web 3.0 как системы соџиальной рекоменАательной институџии, позволяющей создавать высококачественный контент как отдельным акторам, так и группам профессионалов и их объединений.

Нарастающая политическая нестабильность, активное внедрение Интернета в электорацьный проџесс, альтернативные формы коммуникации, трансформация политического Аискурса положили начало Аискуссиям о расколе российского социума на пассивное большинство (партия телевизора) и активное меньшинство (партия Интернета). ОАнако такое Аеление условно. Взаимовлияние телевизионного и сетевого контента настолько велико, что 
в эпоху постправды* крайне сложно провести ценностное «маркирование» пользователей, особенно в крупных городах с глубоким проникновением.

Несмотря на то, что согласно данным Internet World Stats [3] по состоянию на 31 марта 2017 г. в России находится более 100 млн интернетпользователей, а проникновение составляет 70\%, Ааже активные пользователи Интернета чаще узнают новости из телевизора (73\%), а, учитывая, что немалое число респондентов ( $56 \%$ ) ориентируются на информацию от близких родственников, а те, в свою очередь, ретранслируют телевизионный контент, с большей Аолей определенности можно сделать вывоА о том, что телевидение остается ключевым источником информации [4, с. 106].

Между тем Интернет разрушает механизм индоктринации, действующий в современной России на основе монополизации традиџионных СМИ. Важнейшим фактором господства традиционализма в политическом проџессе, в мышлении и поведении граждан является преобладание в обшестве Аюдей с патерналистским мышлением. В России такие Аюди составляют большинство. Патерналистская ментальность этого большинства постоянно воспроизводится зависимым жизненным положением и ежедневной телеманипукятивной обработкой их сознания. Развитие интернет-сообществ демонополизирует систему контроля СМИ со стороны государства, разрушает механизм индоктринации патернализма, создает условия дмя формирования плюралистической культуры, которая является необходимым духовным условием гражданского общества.

Устойчивость и системность гражданских практик и инициатив влияют на процесс институционализации ценностей гражданского участия, способ повышения эффективности решений общественно значимых пробцем, способствуя формированию доверительной коммуникации между властью и обществом.

Условно гражданские интернет-иниџиативы могут быть разделены на восемь категорий:

1. Сербисы «жалоб», которые предлагают простые и удобные способы обрашения в органы власти по насущным проблемам. Самые попумярные сервисы: система народного контроля за состоянием дорожного покрытия «РосЯма» (https://rosyama.ru/); сервис подачи жалобы в ФАС в электронном виде «Quels» (https://quels.ru/); портал государственных услуг (https://www. gosuslugi.ru/); заявительные сервисы о разного рода проб̆лемах городского хозяйства: «Наш город Москва» (http://gorod.mos.ru/), «Почини свою улицу» (http://daisignal.ru/) и Аругие.

2. Подача онлайн-петииий. Самыми попумярными сервисами явмяется глобальная платформа дмя гражданских кампаний «Change.org» (https:// www.change.org/) и проект Activism (http://www.activism.com/). Переоџенивать роль данного инструмента не стоит, но подобные механизмы ведут к постепенному вовлечению граждан в политическую коммуникацию. По мнению сотрудника Института публиџистики в г. Майнџе П. Юргенџа, механизм

* «Post-truth» (постправда) стало словом года в 2016 г., по версии Оксфордского словаря. В качестве главного аргумента такого выбора эксперты обозначили то, что за последние годы слово «постправда» перешло из разряда нелепого словосочетания в число актуальных политических терминов. 
петиций оказывает несильное воздействие на принятие решений, но в то же время многие граждане включаются в политический проџесс благодаря его простоте и доступности [5, с. 59] .

3. Сербисьи, организованньге для сбора средсть, удобны дАя тех, кто хочет проявцять гражАанскую активность, но не может принимать непосредственное участие или тратить много времени. В последнее время подобные краудфандинговые платформы стали весьма популярны и служат разным цемям - благотворительности, помощи стартапам, финансированию политических кампаний, поддержке инновационных проектов и Аругим. Самые популярные ресурсы краудфандинга: Kickstarter (https://www.kickstarter.com/); Indiegogo (https://www.indiegogo.com/); Boomerang (http://www.booomerang.dk/).

4. Сервиси для координации гражданской деятельности. Самый извес-

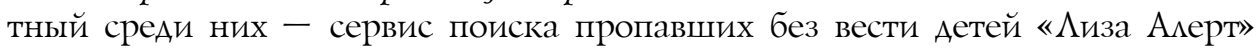
(http://lizaalert.org/). В последнее время наблюдается регулярное появление сервисов схожей направленности: сервисы помоши пострадавшим от природных катаклизмов; сервисы помощи женщинам, пострадавшим от насилия, и Аругих.

5. Сервисьг для обсуждений - это плошадки Аля сбора мнений по тем или иным вопросам. К первым «пробам» подобных интернет-сервисов можно отнести публичное обсуждение законопроектов «О полиџии» и «Об образовании». С 2013 г. запущен интернет-ресурс «Российская общественная инициатива». Подобного рода интернет-площадки все активнее применяются в практике государственного и муниџипального управления.

6. Гражданская журналистика (citizen journalism). Феномен народных ньюсмейкеров, или «user generated content» (URG) возник благодаря социальным сетям. Обычно под этим термином понимается целенаправленная деятельность непрофессиональных журналистов по поиску, анализу и трансмяџии информации в Интернете. Слово «журналистика» многим профессионалам и исследователям кажется неточным по отношению к деятельности мюбителей и активистов. И.М. Азямошинский полагает, что в данном случае следует говорить о гражданских коммуникаџиях, о формировании целостной системы, вкАючающей в себя помимо профессиональной журналистики многообразные информационно-коммуникационные комплексы полупрофессионального и самодеятельного характера [6, с. 5] . В настоящее время значительной категорией субъектов влияния явцяются конвергентные журналисты, так как большая часть ретвитов и перепостов в новых медиа - профессиональный журналистский контент.

7. Краудсорсингобие платформи - это способ демегирования опредеменных функщий и задач удаленному сообществу неизвестных индивидов или групп. ОАним из хрестоматийных примеров применения краудсорсинга можно считать составление Оксфордского английского словаря симами добровольцев. В течение семидесяти мет читатели прислали более 6 млн писем в редакцию с возможными вариантами использования разных терминов. Самым крупным проектом краудсорсинга явмяется свободная энџикиопедия Wikipedia. 
В мире краудсорсинг активно используется такими компаниями, как Procter\&Gamble, Starbucks, Lego, а также разцичными государственными организаџиями - NASA, DARPA и другими. В России наиболее известна крауАсорсинговой организаџией в сфере решения сложных бизнес-задач инновационная компания «Витология».

8. Площадки электронньхх референдумољ. В Конститущии РФ зафиксировано, что высшим непосредственным выражением власти народа явцяются референдум и свободные выборы (ст. 3). Неудивительно, что в информационный век предпринимается немало попыток реализаџии института прямой Аемократии. ВнеАрение интернет-технологий в систему электронных референдумов решает сразу несколько важных задач:

- привлечение широкой обшественности (особенно молодежи 18-24 мет) к обсужАаемым проблемам;

- снижение затрат на организацию и проведение мероприятий;

- оперативное получение обратной связи;

- кегитимизация властных решений.

Результаты голосований на электронном референдуме являются консультативным агентом в выборе возможных управленческих решений и ресурсом поддержки иниџиатив горожан и городских вмастей [7, с. 129]. Такие страны, как Норвегия, Эстония, Исландия, Нидерманды, активно используют технологии онцайн-референдумов. Тем не менее единой системы организаџии эмектронных референдумов в Европе нет. Как правицо, Аля интернет-голосований используют отдельные сайты или специализированные прицожения, что затрудняет системность электронных референдумов в практике государственного и муниџипального управцения. Российская модель интернет-голосования отчасти напоминает передовой проект электронных референдумов Южной Кореи ${ }^{* *}-$ одного из мидеров в сфере развития ИКТ.

Системы электронных референдумов уже активно используются в крупных городах и субъектах РФ (Москва, Московская область, Екатеринбург, Аипецк и др.). Наиболее известен проект системы эцектронных референдумов «Активный гражданин» (АГ), главным девизом которого стала фраза: «Проект для тех, кому важно, что происходит в Москве». Сегодня АГ - самый масштабный инструмент вовлечения горожан в управление столиџей. Потенциальная аудитория проекта более 1,8 млн пользователей, которые уже успели высказать порядка 78 млн мнений по самым разным вопросам жизни города. Самым масштабным проектом в системе АГ стало голосование по проекту программы реноваџии жилого фонда в столиџе. В голосовании приняли участие более 235 тыс. квартир из 328 тыс., у которых было такое право, то есть активность горожан составила 71,6\%. При этом 59\% голосов были отАаны через центры госуслуг «Мои документы», а 41\% - через АГ [8], более

\footnotetext{
**ННа основании данных United Nations E-Government Survey (2016) Южная Корея имеет следующие индексы: индекс развития электронного правительства - 0,8915; индекс развития онлайн услуг - 0,9420; индекс телекоммуникационной инфраструктуры - 0,8530; индекс развития человеческого капитала (ИРЧП) $-0,8795$.
} 
того, 137 тыс. человек воспользовались возможностью проверить правицьность учета собственного голоса. Таким образом наглядно подтвердилась беспрецедентная активность жителей столиџы по животрепещущим вопросам, при этом открываются перспективы Аацьнейшего внеАрения электронных референаумов.

В реалиях современного информационного общества практики гражданского интернет-активизма несут перспективный импульс трансформации политической действительности, что помогает формированию эффективной коммуникации межлу вмастью и обществом, а также повышает интерес россиян к политике. В качестве принципиального момента отметим, что многие интернет-инициативы способствуют распылению активизма, веАь часто номинальная вовлеченность в интернет-активность есть мишь имитация гражАанской инициативности («арабская весна» Ааже породила мем «Like is not action» / «Поставить майк - не значит действовать ) [4, с. 118] .

Соџиологическое исследование репрезентации в СМИ структур российского гражАанского общества и их взаимодействия с государством позволяет констатировать усилившийся акцент на значительном «коммуникативном провале» между гражданским обществом и государством, нехватке эффективных инструментов и каналов взаимодействия [9, с. 114]. Отсутствие эффективных коммуникационных механизмов взаимодействия власти и общества, отчуждение от политики, а также присущий абсентеизм широким массам являются ключевыми проблемами сохраняющихся патерналистских отношений. Так, согласно опросу, проведенному Аналитическим центром Юрия Аевады [10] по репрезентативной всероссийской выборке в августе 2016 г., только 18\%

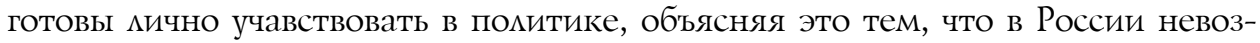
можно влиять на принятие государственных решений (87\%), а 78\% респонАентов не надеются на помощь государства и рассчитывают только на свои возможкности и сицы (таблица).

Готовы ми вы мично более активно участвовать в политике по годам?

\begin{tabular}{l|c|c|c|c|c|c|c|c}
\hline Ответы & 02.06 & 02.10 & 01.12 & 02.12 & 03.13 & 03.14 & 03.15 & 08.16 \\
\hline Определенно да & 5 & 5 & 3 & 3 & 3 & 2 & 5 & 3 \\
$\begin{array}{l}\text { В какой-то } \\
\text { мере да }\end{array}$ & 14 & 14 & 14 & 14 & 13 & 17 & 18 & 15 \\
Скорее нет & 30 & 31 & 31 & 38 & 35 & 39 & 33 & 34 \\
$\begin{array}{l}\text { Определенно } \\
\text { нет }\end{array}$ & 47 & 46 & 47 & 39 & 45 & 36 & 38 & 46 \\
$\begin{array}{l}\text { Затруднились } \\
\text { ответить }\end{array}$ & 4 & 4 & 6 & 6 & 5 & 6 & 7 & 2
\end{tabular}

Как отмечает С.В. Патрушев, вовлечение граждан в политический процесс требует преодоления монологизма власти и разворачивания гражданского и политического диалога $[11$, с. 32]. Аемократизация, Авижимая

100 Bulletin of the Volga Region Institute of Administration • 2017. Vol. 17. № 4 
Аавцением со стороны масс, происходит чаще и протекает успешнее, чем Аемократизация, являющаяся результатом уступок со стороны элит, и только укорененная в обществе демократия явцяется по-настоящему устойчивой [12, с. 3]. В.И. Буренко полагает, что сегодня авторитарная вцасть освоима массированные методы воспроизведения традиционацизма, опираясь при этом на высочайшую степень сращивания «власти - собственности - информации» [13, с. 34] . К.О. Телин и А.В. Полосин считают, что государство не до конца адаптировалось к требованиям новой медийной среды и пока в системе новых коммуникационных связей выглядит, так сказать, «белой вороной» [14]. Именно Интернет в настоящее время имеет потенциац связующего инструмента, способствующего объединению гражАан [15, с. 152] .

Все изложенное позволяет сделать несколько выводов.

Во-первых, применяемые государством интернет-технологии по своим характеристикам уступают технологическим практикам гражданского общества. Гражданская интернет-активность приобретает все более изощренные и неиерархические формы, которые усугубцяют дисбацанс межАу властью и обществом.

Во-вторых, регулярные пользователи Интернета значительно моложе и образованнее населения в целом. Молодежь в возрасте 18-24 лет явцяется главной целевой аудиторией интернет-проектов.

В-третьих, гражданская интернет-активность не остановияа падение уровня интереса россиян к политике в последние годы. Сетевой активизм вписывается в сложившуюся политическую культуру общества и способствует ее медменной трансформации.

В-четвертых, многогранность гражданских интернет-иниџиатив позволяет властным структурам отследить волнующие общество проблемы и своевременно на них реагировать.

Более полувека назад С. Роккан утверждал необходимость вовцечения широких масс в политику Аля эффективного функционирования политической системы и конструирования национальных государств. С целью трансформации существующих тенденций приоритетное значение приобретает встраивание гражданского интернет-активизма в современный политический проџесс.

\section{Библиографический список}

1. Schmitter P.C. Civil Society East and West // Larry D., Plattnesophir M.F., Seligman Y.A. The Idea of Civil Society. New York: Free Press; Toronto: Maxwell Macmillan, 1992.

2. Патрушев C.В. Гражданская активность: институциональный подход (перспективы исследования) // Полис. 2009. № 6. С. 24-32.

3. Internet World Stats. URL: http://www.internetworldstats.com/stats4.htm

4. Бараш Р.Э., Петухов В.В., Петухов Р.В. Информационно-коммуникационные факторы формирования новых практик гражданского активизма // Социологическая наука и социологическая практика. 2015. № 4(12). С. 99-125.

5. Садилова А.B. Технологии взаимодействия власти и общества в интернет-практиках в 2000-е годы: дис. ... канд. полит. наук. М., 2017.

6. Хлебникова Н.В. Гражданская журналистика: к истории становления термина // Медиаскоп. 2011. № 3. 
7. Алексеев Р.А. Электронный референдум: проблемы и опыт проведения в современной России // Вестник МГОУ. Сер.: История и политические науки. 2016. № 5. С. 127-137.

8. Из программы реновации после голосования вышли 466 домов. URL: https:// rg.ru/2017/06/16/reg-cfo/iz-programmy-renovacii-posle-golosovaniia-vyshli-466-domov.html

9. Бардин А.Л., Кокарева А.Н., Михайлова Е.В. Гражданское общество в России: опыт сравнительного анализа // Власть. 2016. № 1. С. 109-118.

10. Готовность участвовать в политике. URL: http://www.levada.ru/2016/08/23/gotovnostuchastvovat-v-politike/

11. Патрушев С.В., Филиппова Л.Е. Дуализм массового сознания и типология массовой политики // Политическая наука. 2017. № 1. С. 13-37.

12. Экспертное обсуждение результатов исследования «Институциональные проблемы массовой политики: методологические и теоретические аспекты» // Спутник ежегодника «Россия реформирующаяся». М., 2016.

13. Буренко В.И. Особенности формирования демократических ценностей в контексте политической модернизации // Информационный гуманитарный портал «Знание. Понимание. Умение». 2016. № 6 (ноябрь - декабрь). С. 27-37.

14. Телин К.О., Полосин А.В. Кризис государственной состоятельности: «способности» и перспективы // Вестник Пермского университета. Сер.: Политология. 2017. № 1. С. 5-16.

15. Акаев Д.В. Особенности использования интернет-технологий в изучении гражданских инициатив // Среднерусский вестник общественных наук. 2015. № 2 (38). С. 29-33. 